\title{
RESTRIÇÕES ASPECTUAIS À DISTRIBUIÇÃO DO ADVÉRBIO BAIXO MUITO*
}

\author{
ANA PAULA QUADROS GOMES ${ }^{1}$ \\ (UFRJ)
}

\begin{abstract}
RESUMO: Embora a posição de muito (PB) em SVs (sintagmas verbais) seja invariável, há restrições ao seu licenciamento, até agora pouco descritas na literatura, que levantam uma questão ainda sem resposta: por que sua inserção em diversas sentenças gera agramaticalidade $\left({ }^{*}\right.$ Finalmente encontrei $\underline{\text { muito a chave que eu tanto procurava, }}{ }^{*} \mathrm{O}$ bebê de Maria nasceu muito hoje, ${ }^{*}$ Ronaldo marcou muito um gol nessa partida etc.)? Neste artigo, argumentamos que os motivos para os casos de não-licenciamento de muito não são sintáticos. Propomos uma condição semântica para o seu licenciamento, com base em Doetjes (2008). Defendemos que muito faz seleção semântica: seleciona expressões graduáveis (cf. KENNEDY; McNALLY, 2005, para very - inglês). Mais especificamente, muito seleciona grau nãomáximo em uma dimensão licenciada pelo verbo. Mostraremos que sentenças com muito modificador de SV não serão bem formadas quando o predicado verbal não tiver graus, e que a interpretação das bem formadas será sempre de grau não-máximo. Sentenças com muito no SV não podem descrever um episódio único completo, caso a dimensão em que ocorre a marcação de grau seja a progressão para a culminância. A iteratividade, leitura típica de muito em SVs, é uma continuidade indefinida: não se pode aferir o número máximo de ocorrências do evento durante o intervalo temporal considerado, o que equivale a uma soma vaga, não-máxima. Defenderemos que muito produz sempre escalas nãomáximas: em dimensões aspectuais, isso implica ou a atelicidade ou a imperfectividade.
\end{abstract}

Palavras-chave: muito, advérbios baixos, modificadores de grau, aspecto verbal

ABSTRACT: Although muito (BP) always appears in the same position, its licensing inside VPs is subject to restrictions, still poorly described by the literature. Those restrictions raise important questions, which remain yet to be answered. The explanation for the ungramaticallity of muito in VPs (*Finalmente encontrei muito a chave que eu tanto procurava, ${ }^{*}$ O bebe de Maria nasceu muito hoje, * Ronaldo marcou muito um gol nessa partida etc.) is still to be given. This data in which the insertion of $\underline{\text { muito }}$ is not licensed is not amenable to a syntactic explanation. We assume a semantic condition for the licensing of $\underline{\text { muito }}$, following Doetjes (2008). We claim that s-selection applies: muito can only modify degree expressions (cf. KENNEDY; McNALLY, 2005's analysis of very). Specifically, muito selects a non-maximal degree in some dimension contributed by the verb. We aim to show that all the well-formed sentences containing muito in the VP are non-maximal degree predicates. If licensing $\underline{\text { muito }}$ as a modifier, a VP will never describe a single ("once only") and culminated episode, given that in those cases the modified degree dimension is the progression towards culmination. Iterative

* Sou imensamente grata a dois pareceristas anônimos, designados pelos Cadernos de Estudos Linguísticos, por suas valiosas contribuições para o aprimoramento deste artigo. Agradeço também, pela leitura do draft, antes da submissão à CEL, e pelos seus preciosos comentários, Roberlei Alves Bertucci (UTFPR) e Roberta Pires de Oliveira (UFPR/UFSC).

${ }^{1}$ anaquadrosgomes@1etras.ufrj.br 
readings, typical of $\underline{\text { muito }}$ inside VPs, have an indefinite extension: one does not know the maximal number of episodes referred by the SV, since the time interval in consideration remains open. This counts as a vague, non-maximal sum of episodes. $\underline{\text { Muito }}$ produces non-maximal scales. In aspectual dimensions, it comes to atelicity or imperfectivity.

Keywords: $\underline{\text { muito }}$ (BP), low adverbs, degree modifiers, verbal aspect

\section{INTRODUÇÃO: O LICENCEAMENTO DE MUITO EM SVs}

Para a cartografia (CINQUE 1999 e seguidores), muito é um advérbio baixo. Diferentemente de advérbios altos, como frequentemente, que são linearizados em diversos lugares da sentença, muito é praticamente inamovível. ${ }^{2}$ Cinque (1999) inicialmente localizou molto (italiano) com os advérbios de maneira, abaixo dos de frequência e dos modais. Vecchiato (1999) propôs para beaucoup e peu (francês) outra posição: esses intensificadores são precedidos por tout (o completivo), mas precedem bien (o advérbio de modo). ${ }^{3}$ Outros, como Laenzlinger e Soare (2005), defendem uma projeção específica para advérbios de intensidade como muito, chamada de Aspect Degree. Os autores observam que os advérbios temporais, os de frequência e alguns dos de maneira podem ser topicalizados, mas não é possível mover os de intensidade, para eles advérbios quantificacionais de aspecto baixo, como $\underline{\text { mult }}$ (romeno) e intensamente (espanhol). As diversas análises convergem quanto ao congelamento de muito na posição em que é gerado.

\footnotetext{
${ }^{2}$ Como observado por um dos pareceristas, a quem agradeço, embora o advérbio muito do PB apareça mais naturalmente à direita do verbo (Dormi muito / * Muito dormi), há contextos em que ele é perfeitamente gramatical à sua esquerda. Atestadamente, em adágios/provérbios (Macaco que muito mexe quer chumbo), em estruturas relativas e em subjetivas encabeçadas por quem (Quem muito quer nada tem), assim como em construções com o se de indeterminação do sujeito (Muito se fala em sustentabilidade, mas pouco se faz por ela). Chama a atenção o fato de esses contextos licenciadores envolverem períodos complexos, com orações encaixadas ou coordenadas, o que levanta a suspeita de que se trate de recurso mais próprio da língua escrita e da fala culta, a dos mais escolarizados. Nos períodos simples, entretanto, que são os mais usuais no nosso vernáculo, colocar muito antes do verbo soa pouco natural (compare-se Nós dançamos muito a * Nós muito dançamos). Talvez estejamos em meio a um processo de mudança: provérbios são reconhecidos por conservar estruturas gramaticais de outros tempos, e a escrita é tida como mais conservadora que a fala cotidiana. Além disso, observe-se que, nos exemplos em que muito precede o verbo, ou aparece a ênclise, nada usual em nosso vernáculo, ou parece haver um elemento de atração (que, quem). Já foi bastante observado, para pronomes pessoais, que "atratores" ainda atuantes no PE perderam sua força no PB. Seja como for, uma análise sintática do advérbio muito foge ao escopo deste artigo, que vai apenas discutir fatos de sua distribuição essenciais para delinear uma análise semântica. O parágrafo de abertura pretende apenas pontuar que, apesar de haver diversos trabalhos sobre a sintaxe de muito e correlatos em outras línguas, o tema não vem despertando o interesse de sintaticistas ultimamente.

${ }^{3}$ Essa ordem relativa descreve em termos gerais o PB, como é visível no SN: todos os seus muito

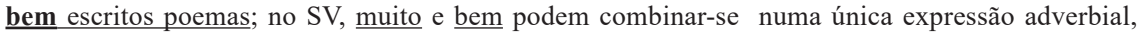
nessa ordem ( $\underline{\text { João comeu muito bem, }}$ * João comeu bem muito); não é permitida a composição dos três advérbios: *João comeu todo muito bem (em João comeu tudo muito bem, a modificação é feita exclusivamente por muito bem: tudo não é parte do modificador, mas é o argumento interno do verbo). É fato observado por vários autores, incluindo Lemle (1994), que os indefinidos todo e muito não coocorrem em PB, e que a posição de todo é sempre a mais externa (todas as muitas cartas $\underline{\text { chegaram }},-$ muitas $=$ numerosas - , muita carta chegou, toda carta é importante, mas * toda muita carta é manuscrita).
} 
Malgrado essa rigidez estrutural, SVs com muito têm múltiplas interpretações. Por exemplo, Neymar está jogando muito pode ser entendida como (i) um elogio à sua performance, (ii) um comentário sobre a frequência com que ele entra em campo. Seria interessante explicar estruturalmente essas interpretações. É o que Fleischhauer $(2010,2016)$ propõe para beaucoup (francês): antes do verbo principal, beaucoup indica frequência; após, intensidade. Mas não se pode verificar se esse é o caso de muito,${ }^{4}$ pois não se pode movê-lo livremente. ${ }^{5}$ Um fato curioso é que a inserção de muito em numerosas sentenças é agramatical: ${ }^{6}$

(1) Entardeceu (*muito) às $16 \mathrm{~h}$ ontem em Varsóvia.

(2) No verão, às 5 h30, o sol já raiou (*muito).

(3) Certo dia, o tal tufão varreu (*muito) aquela cidade do mapa.

(4) João deu (*muito) esse livro de presente para a Maria ontem.

(5) Seu cliente telefonou (*muito) há $10 \mathrm{~min}$.

(6) A Tocha Paralímpica chegará (*muito) amanhã ao Rio de Janeiro.

(7) O bebê de Maria nasceu (*muito) hoje.

(8) Neste exato momento, João está (*muito) na Itália.

As sentenças acima são todas perfeitamente bem-formadas na ausência de muito. O que barra sua inserção? O número de argumentos não é um fator: o verbo em (1) não requer argumento algum, o de (2) é monoargumenta1, o de (3) pede dois argumentos, e o de (4), três. Muito também não distingue inergativos (5) de inacusativos (6). O tempo verbal também não é o fator decisivo para a distribuição de muito, pois sentenças no futuro (6), passado (7) e presente (8) rejeitam sua inserção. ${ }^{7}$ Não há generalização óbvia.

\footnotetext{
${ }^{4}$ Propor posições de base distintas, sem poder checar isso com testes de movimento, seria uma solução ad hoc, sem grande poder explicativo.

${ }^{5}$ Por exemplo, não é opcional dizer * muito choveu em vez de choveu muito, e uma forma não licenciada não pode veicular um sentido específico. Em PB, uma tal especialização interpretativa é observada na ordem dos adjetivos: pobre menina rica (digna de dó) versus menina pobre (sem dinheiro), mas não se aplica a muito em SVs.

${ }^{6}$ Por agramaticalidade, seguindo Chierchia (2013), estamos entendendo a impossibilidade de obter a leitura relevante. Para os dados de (1) a (8), o leitor deve adotar a interpretação de um episódio único, assumindo que o evento descrito ocorra uma única vez. Leituras iterativas salvariam as sentenças, como será discutido adiante.

${ }^{7}$ Como apontado por um dos pareceristas anônimos, a quem muito agradeço por isso, o tempo tem muita importância. O presente é um dos ingredientes da leitura habitual/iterativa. Da mesma forma, o aspecto perfectivo é um ingrediente importante da leitura episódica, de evento ocorrido uma única vez. Entretanto, não é possível sustentar que muito opere apenas com SVs neste ou naquele outro tempo verbal, o que nos leva a prosseguir com a investigação sobre a s-seleção de muito, procurando por respostas mais complexas, resultantes de mais componentes, além do tempo, como o aspecto.
} 
Muito foi objeto de interesse de Doetjes (2008). Essa autora desenha um contínuo de categorias que podem ser modificadas por expressões graduais, "intensificadoras"/“quantificadoras": (i) adjetivos (graduais), (ii) verbos graduais, (iii) verbos eventivos, (iv) nomes de massa e (v) nomes contáveis plurais. ${ }^{8}$ Ela chama de modificadores do tipo A expressões especializadas em uma só categoria, como very (inglês), o qual c-seleciona apenas adjetivos. Já as expressões de tipo B transitam por duas categorias contíguas; erg (holandês) modifica somente adjetivos e verbos graduais. As expressões de tipo $\mathrm{C}$ não fazem seleção categorial alguma, embora façam obrigatoriamente seleção semântica (s-seleção): só modificam expressões de grau, seja em que domínio for. Entre elas, Doetjes inclui trop (francês), less (inglês) e muito (português). "Expressões do tipo $\mathrm{C}$ tanto podem funcionar como intensificadores como indicar um grau de quantidade" (DOETJES 2018, p.127). Podemos ilustrar a leitura intensificadora com (i) o café está muito quente (adjetivo), (ii) esquentou muito hoje (verbo gradual) e (iii) o ônibus está correndo muito (verbo eventivo, leitura de velocidade alta); para ilustrar a leitura quantitativa, temos (iv) Amim foi muito eleito governador em Santa Catarina (verbo eventivo, leitura de número de episódios), (v) há muita áqua na cisterna (nome massivo, leitura de volume) e (vi) tem muitos carros na rua (nome contável plural, leitura de cardinalidade). Muito modifica expressões graduais, desde adjetivos de grau até nomes plurais, passando por verbos graduais, verbos eventivos e nomes de massa. Neste artigo, examinaremos apenas SVs (verbos graduais e eventivos, nos termos de Doetjes).

Para tratar muito, utilizaremos uma semântica escalar/de graus, na linha de Kennedy e McNally (2005), para quem um adjetivo de grau (AG) é uma comparação implícita, com um dos elementos comparados não-realizado abertamente. Um AG é uma função que mapeia seu argumento a um grau na escala relevante. Uma escala é um conjunto de graus ordenados de certa propriedade. Por exemplo, em Pedro é alto, alto mapeia Pedro ao grau da escala de ALTURA equivalente à sua medida, $1,8 \mathrm{~m}$. Um morfema comparativo não-pronunciado, chamado de pos, introduz o outro grau da comparação, o do parâmetro. Podemos dizer Pedro é alto considerando que ele é alto para um brasileiro, comparando o grau de altura de Pedro $(1,8 \mathrm{~m})$ ao $1,7 \mathrm{~m}$ desse parâmetro (o brasileiro médio). Pos também estabelece a ordem relativa entre os graus. No caso de alto, o grau do argumento do adjetivo tem de ser o maior na comparação. Por isso, para quem tomar do contexto um parâmetro como, por exemplo, os jogadores de basquete, que têm em média $2,1 \mathrm{~m}$, a sentença será falsa. Nessa teoria, os intensificadores

\footnotetext{
${ }^{8}$ Segundo a autora, translinguisticamente, essas expressões modificadoras só podem modificar categorias vizinhas nessa lista de gradação, ou seja, não haverá em língua natural alguma um modificador que se aplique, por exemplo, apenas à dupla adjetivos e nomes de massa.

${ }^{9}$ Os testes para identificar os adjetivos de grau são colocá-los em comparativas (Ele é mais alto que ela/ \# A lua é um corpo mais celeste que o sol), verificar se aceitam intensificação (Ele é um moço

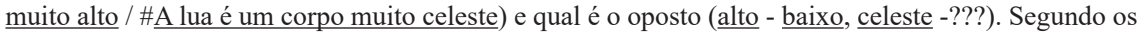
testes, alto é um adjetivo de grau, mas celeste não é.
} 
são modificadores de grau, pois só modificam AGs (muito alto, ${ }^{*}$ muito pronto) e operam sobre a comparação, acrescentando exigências. Por exemplo, Pedro, de $1,8 \mathrm{~m}$, pode ser considerado alto para um brasileiro sem que seja considerado muito alto. Isso porque muito exige uma distância mais significativa entre os graus comparados, embora mantenha o requisito do adjetivo (de que o argumento exiba o maior grau na comparação). Há tipos lógicos possíveis para as escalas: elas podem ser (i) abertas, como é o caso de alto, em que não se sabe de antemão se o parâmetro contextual fornecerá a ponta inferior ou superior do segmento da escala; ou (ii) fechadas, se o parâmetro, previamente definido, não variar. Nas fechadas, os adjetivos tomam como parâmetro uma dimensão do seu argumento. Por exemplo, a gaveta estará fechada caso seu tampo e a face do armário se alinhem. A gaveta está fechada exige igualdade entre a posição atual da gaveta e zero graus de abertura. Fechada requer igualdade entre os graus de comparação, o que resulta num grau máximo. Com todos os outros graus, a gaveta será considerada aberta. Distando $2 \mathrm{~cm}$ do armário, ela pode ser julgada aberta, mas não muito aberta. Muito é, portanto, um modificador de graus cujo papel é reconfigurar o segmento de escala resultante da comparação, somando novos requerimentos aos do adjetivo.

Somente as dimensões graduáveis dos adjetivos são tratadas por Kennedy e McNally (2005). Nós estendemos sua proposta a outros domínios, assumindo uma única semântica para o modificador muito, seja em sintagmas adjetivais ou verbais. Sanchez-Mendes (2015) fez um percurso semelhante ao tratar de pitat, um modificador de graus do Karitiana que atua em todos os domínios. Hackl (2000) já havia proposto um mesmo tratamento para os quantificadores comparativos nos diversos domínios. Rett (2008) também apresentou uma análise única para modificadores de grau ( $m$-words, operadores de medição) que atuam em várias construções, de diferentes domínios. A ideia de fazer um paralelo entre domínios remonta a Bach (1986), que tratou das semelhanças entre o nominal e o verbal.

Queremos prever os casos em que muito será (a)gramatical no SV. Para prever que leitura encontraremos nos SVs em que muito é licenciado, se quantificacional (de frequência ou emissão de substância, como será detalhado mais adiante) ou intensificacional (de grau), devemos distinguir as fontes de gradação para SVs. Se quisermos explicar a distribuição de muito por sentenças assumindo que muito faz seleção semântica do material que modifica (cf. DOETJES 2008), precisaremos saber como determinar independentemente quais os SVs que ele pode modificar. Em outras palavras, teremos de saber quais predicados verbais são escalares/graduais.

Neste artigo, temos como objetivo apresentar um conjunto de fatos empíricos sobre a distribuição de muito em SVs, para então propormos um tratamento teórico que dê conta da distribuição e do licenciamento desse advérbio. Defenderemos que todo um conjunto de fatos empíricos é explicável por seleção semântica. O artigo se organiza como segue: na seção (1), apresentaremos evidências de que há SVs em que a inserção de muito resulta em má formação, e trataremos de buscar critérios para organizar os dados examinados; nessa 
trajetória, caracterizaremos em (1.1) as leituras de pluralidades de episódios, iterativas, como típicas de muito, propondo isolá-las para examinarmos o comportamento de muito em classes acionais vendlerianas que expressam um episódio singular; tal estratégia tornará saliente a incompatibilidade de muito com leituras de eventualidades culminadas, o que está vinculado à exclusão mútua entre complementos quantizados de accomplishments e muito, discutida em (1.2); e à dificuldade de conciliar muito e SVs achievements, tratada em (1.3). Em (1.4), examinaremos muito com verbos de medida, para reforçar nossa análise de muito como marcando um grau alto e vago numa dimensão escalar verbal; assim concluímos, com o fim da seção (1), o exame das leituras quantificacionais geradas por muito dentro do SV. A seção (2) vai tratar das leituras intensificacionais, passando pelos Degree Achievements (subseção 2.1) e pelos demais fatores geradores desse tipo de interpretação (subseção 2.2.). Na seção 3, retomamos o comportamento de muito traçado nesse percurso, segundo a nossa proposta de análise.

\section{DESVENDANDO A S-SELEÇÃO DE $\underline{\text { MUITO }}$}

Vamos começar pelas classes acionais vendlerianas. Essas classes não se aplicam aos verbos em si, mas aos SVs, ao sintagma que inclui o verbo e seu complemento, exatamente o domínio de modificação que nos interessa. Vendler (1967) propôs quatro classes semânticas: estados (acreditar, amar...), atividades (correr, nadar...), accomplishments (onstruir uma casa, fazer um bolo...) e achievements (cair, ganhar as eleições...). Elas são distinguidas pelos traços homogeneidade (presente apenas em estados e atividades), dinamismo (ausente apenas de estados), duração ou processo (ausente apenas de achievements) e culminância (presente apenas em accomplishments e achievements). Vejamos se muito é sensível a elas:

(9) Amo muito tudo isso. (slogan do McDonalds) (estado)

(10) O professor por quem você procura deve estar (*muito) na sala da direção neste exato momento. (estado)

(11) João fuma muito. (atividade)

(12) Quando João entrou, Maria estava vendo (*muito) a novela. (atividade)

(13) O vizinho, que é engenheiro, construiu (*muito) esta ponte. (accomplishment)

(14) O médico curou (*muito) a minha bronquite. (accomplishment)

(15) Após uma viagem de 3 dias, Pedro alcançou (*muito) o topo da montanha. (achievement)

(16) Da Vinci desenhou (*muito) a Monalisa bem no centro da tela. (achievement) 
Não é trivial identificar o traço selecionado por muito. Como temos um SV de estado em que a modificação por muito é permitida (9) e outro em que é inaceitável (10), temos de descartar o traço dinamismo como governando a distribuição de muito. Quanto às atividades, também em um caso a modificação por muito é aceitável (11) e em outro (12) não é. Isso descarta o traço homogeneidade. Accomplishments $(13,14)$ não admitem a inserção de muito. $\mathrm{O}$ traço relevante não é a duração, visto que um estado (10), uma atividade (12), e os accomplishments $(13,14)$ não admitem modificação por muito. A culminância não pode ser o único traço impedidor, pois, embora os achievements $(15,16)$ e accomplishments $(13,14)$, que têm esse traço, não aceitem a inserção de muito, uma atividade (13) e um estado (10) também não, e atividades e estados não culminam. Deve haver então algo além da acionalidade. Não obstante, alguma conexão existe entre o fator de licenciamento da modificação por muito e accomplishments e achievements, pois essas duas classes acionais rejeitam muito. $\mathrm{O}$ que as distingue das demais classes acionais é a telicidade: a dimensão de eventualidades que mede sua progressão para verificar o quanto falta para a sua culminância (telicidade ou quantização, em oposição à cumulatividade, nos termos de Krifka, 1998), progressão que atinge seu grau máximo ao término do processo. Eventualidades télicas, culminadas/quantizadas, são, portanto, marcadas por um grau máximo nessa dimensão. Os fatos indicam que a telicidade, longamente associada na literatura às classes acionais dos achievements e accomplishments, bloqueia a inserção de muito. Nenhuma leitura é produzida por muito em $(13,14,15$ e 16). Nem a de múltiplos eventos, nem outras, como, por exemplo, para (13), a interpretação de que a ponte foi construída com muito esforço, com alto dispêndio de recursos, ou em tempo recorde. Exploraremos essa pista. Porém, antes de irmos mais a fundo, vamos examinar uma quinta classe acional, a dos semifactivos.

\subsection{Classes acionais e somas de eventualidades}

Smith (1991) introduz a classe dos semifactivos, que apresentam "episódios de atividade", "eventos dinâmicos, instantâneos e atélicos" (cf. ROTHSTEIN, 2004). Esses SVs, como as atividades, são dinâmicos e atélicos, mas, como os achievements, são instantâneos, ou seja, são intervalos mínimos de mudança de estado (cf. WACHOWICZ 2006). Muito combina com eles:

(17) A bola quicou muito antes de entrar na caçapa.

(18) Eu bati muito à porta antes de ser ouvido.

(19) A torneira está gotejando muito.

Examinando as interpretações das sentenças acima, uma generalização surge: se o SV modificado por muito for semifactivo, sempre será disponibilizada (além de outras) a leitura de pluralidade de episódios. Nessa leitura, muito diz que, internamente a um período de tempo indeterminado, é/foi grande o número 
de episódios de certa natureza, entendidos como eventos culminados (quicadas da bola, batidas à porta, emissão de gotas). Importante: não é possível determinar o total de episódios culminados nas sentenças de (17) a (19). ${ }^{10}$ Semifactivos, sendo pluralidades não-quantificadas, vagas, não têm grau máximo. Vamos postular então que muito não é indiferente à oposição telicidade/ atelicidade, mas seleciona SVs atélicos; prevemos sua incompatibilidade com episódios singulares culminados. A previsão se confirma:

(20) João assistiu muito ao seu espetáculo de dança favorito.

(21) João assistiu (*muito) à minha primeira aula de hoje.

Para (20), é possível uma leitura iterativa, de que João viu e reviu em ocasiões diferentes um mesmo show. Em (21), porém, nosso conhecimento de mundo não nos permite contar duas presenças para o aluno numa mesma aula; esse episódio onceonly não dá margem a leituras iterativas, daí a inserção de muito ser agramatical. O que ocorre em (20) então é que muito elimina a telicidade/quantificidade que a sentença tinha na sua ausência, produzindo iteratividade. A iteratividade toma um episódio culminado télico/quantizado e o multiplica, produzindo uma sucessão de episódios culminados distribuídos ao longo de um período vago; o número de episódios compreendidos naquele período fica incerto, tratando-se de uma soma não-máxima, de uma pluralidade não-quantizada.

Embora usualmente a inserção de muito num SV gere iteratividade, com muito valendo por muitas vezes, sua distribuição não se confunde com o fenômeno da iteratividade. Muito não é um mero pluralizador de eventos. Muito pode modificar predicados singulares, desde que a eventualidade esteja em progresso e não tenha culminado. Como mostram as sentenças de estado e atividade gramaticais com muito, há interpretações de único episódio. Nesses casos, muito age sobre outras dimensões, gerando um grau alto, mas não-máximo, numa escala autorizada pela natureza da eventualidade, produzindo o que se chama tradicionalmente de leitura intensificadora. Por exemplo, João dormiu muito é naturalmente interpretado como um episódio único de sono de João, mas de duração prolongada. A duração é uma das dimensões (traços, na literatura das classes acionais) que muito seleciona, embora não a única. É a leitura de um conjunto de eventos, no caso dos semifactivos, ou de um único evento, no caso de estados (Pedro amou muito Maria pode significar, entre outras coisas, que o amor dele por ela se manteve por anos) ou de atividades (Luís correu muito hoje

\footnotetext{
${ }^{10}$ Uma diferença marcante entre semifactivos, de um lado, e achievements, do outro, é que, uma vez no aspecto perfectivo, estes últimos não permitem leitura de múltiplos episódios, justamente a leitura comum a todos os verbos semifactivos. Achievements são interpretados como um episódio específico, singular. As versões sem muito de $(15,16)$, plenamente gramaticais, expressam um só alcance do topo da montanha, em uma dada ocasião, e a confecção de um único desenho, certa vez. A inserção de muito não cria a leitura de que isso se repetiu. Já a sua inserção em SVs semifactivos produz, entre outras interpretações, a de que a soma dos episódios é grande, pois se estende por uma janela temporal indefinida.
} 
pode significar, entre outras coisas, que a corrida de hoje foi longa) em que um ou mais estados/ eventualidades estende(m)-se por um grande intervalo. Porém, a inserção de muito em accomplishments e achievements não gera leitura de evento único de duração prolongada. Há quem identifique uma leitura iterativa em SVs accomplishments e achievements com complemento quantizado plural (exemplos de Wachowicz, 2006):

(22) Carlos construiu três casas.

(23) Carlos registrou três ângulos da modelo.

(24) Carlos teve dois carros.

(25) Carlos correu dois quilômetros.

Segundo Wachowicz (2006), na leitura iterativa, Carlos construiu três casas sucessivamente, uma por vez (22); e Carlos clicou a modelo três vezes, um clique para cada ângulo (23). A autora destaca que ter um indivíduo plural como complemento não tem o mesmo efeito em SVs de estado (24) e atividade (25): é natural entender que Carlos teve dois carros ao mesmo tempo, em vez de sucessivamente (24); e que Carlos correu uma corrida só, com trajeto total de $2 \mathrm{~km}$ (25). Interessantemente, muito não é licenciado em nenhuma das sentenças de (22) a (25):

(26) a. Carlos construiu (*muito) três casas.

b. Carlos registrou (*muito) três ângulos da modelo

c. Carlos teve (*muito) dois carros.

d. Carlos correu (*muito) dois quilômetros.

Os paradigmas (17-19), (20,21), (22-25) e (26), combinados, mostram que o licenciamento de muito não pode ser confundido com as condições de produção de iteratividade, pois muito não multiplica toda e qualquer eventualidade, não modificando accomplishments e achievements nem mesmo quando eles apresentam complementos que são sintagmas de determinante (SDs) plurais, capazes de lhes valer, na ausência de muito, leituras iterativas. Muito só é compatível com episódios culminados se eles formarem uma pluralidade em número indefinido (17-20).

Uma vez que já tratamos da natureza da iteratividade, propomos, por razões de foco, desconsideraremos, para todos os exemplos das seções seguintes, a interpretação corriqueira em que muito significa muitas vezes. Vamos assumir, no futuro, que cada exemplo descreva um evento único, singular, ancorado em certo ponto do espaço-tempo. Tal estratégia vai nos render uma discussão mais rica. Na próxima seção, examinaremos a natureza da incompatibilidade de muito com complementos realizados. 


\subsection{Sobre a impossibilidade de coocorrência de muito e complemento quantizado}

Como visto na subseção anterior, alguns autores (entre eles WACHOWICZ 2006 e WACHOWICZ e FOLTRAN 2011) assumem que a cardinalidade do complemento tenha efeito sobre o número de episódios: complementos com cardinalidade igual a 1 (Ronaldo marcou aquele gol de gaveta) resultam em leitura episódica singular, e os com cardinalidade maior que 1 (Ronaldo marcou três gols na partida) resultam na leitura iterativa. Entretanto, muito é agramatical com accomplisments e achievements, com qualquer SD, seja ele singular (21) ou plural (26a). Como explicar isso? Justamente pelo efeito da quantização sobre a telicidade do SV dessas classes acionais. A iteratividade e a telicidade são computadas com o complemento incluído. O complemento de um achievement ou accomplishment é quantizado. A troca do complemento SD por um nome nu, cumulativo, altera a telicidade:

(27) a. O engenheiro construiu aquela ponte. (accomplisment)

b. *O engenheiro construiu ponte. (agramatical)

c. O engenheiro construiu pontes (ao longo da carreira). (atividade)

(28) a. Pedro venceu a corrida. (achievement)

b. *Pedro venceu corrida. (agramatical)

c. Pedro venceu corridas (neste campeonato). (atividade)

Os paradigmas (27) e (28) mostram que só com complemento quantizado o predicado é télico. Um teste bastante conhecido é a combinação com sintagmas preposicionais (SPs) medidores do tempo de sustentação de uma atividade ("por $\boldsymbol{x}$ tempo'), que indicam atelicidade, ou SPs marcadores da duração da progressão até a culminância ('em $\boldsymbol{x}$ tempo'), indicadores de telicidade. O teste confirma que SDs conduzem a resultados distintos dos promovidos por nomes nus:

(29) a. O engenheiro construiu aquela ponte em 2 dias $/$ * por 2 dias $/$ *às 14 h.

b. $\mathrm{O}$ engenheiro construiu pontes *em 2 dias/ por 2 dias/*às $14 \mathrm{~h}$ (e depois viajou).

(30) a. Pedro venceu a corrida *em 2 dias/*por 2 dias/ às $14 \mathrm{~h}$.

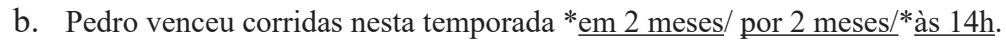

Por ser avesso à telicidade, o esperado é que muito não possa ficar junto com um complemento SD quando a quanticização do complemento tiver efeito sobre a telecidade do SV. De fato, inserir muito nos SVs (29a) e (30a) seria agramatical. No caso de verbos transitivos de estado, o previsto é que não haja problema, porque os verbos transitivos de estado são atélicos. A previsão se confirma: 
(31) a. Maria amou João \#em dois dias/ \#por dois dias/ *às 14h.

b. Maria amou muito João.

A leitura de (31b) não é de quantidade, mas de intensidade: enquanto amou João, Maria o amou profundamente. Complementos SD não produzem telicidade em verbos de estado (31a). Esses fatos desenham a seleção semântica de muito. Esperamos incompatibilidade com SVs télicos lidos como um só episódio culminado. Esperamos a compatibilidade de muito com verbos típicos de accomplishments e achievements apenas na ausência de seus complementos quantizados. De fato, é alta a produtividade de sentenças com muito e transitivos sem o complemento nominal expresso:

(32) a. O engenheiro construiu muito (*as pontes) em um ano.

b. Maria comeu muito (*a travessa inteira) na festa.

c. Silvio Santos alcançou muito (*o sucesso) na vida.

d. O artista daquela obra ali desenhou muito (*os cavalos).

e. Esse atleta venceu muito (*a competição). ${ }^{11}$

Nas sentenças (32), só é possível ter muito quando o SD complemento não é pronunciado. O SD complemento pode ser realizado se muito for apagado. O muito de (32) é invariável: ${ }^{12}$ continua sendo um modificador de SV. A tradição gramatical (TG) não dá nenhuma explicação para o apagamento desses complementos quando o modificador muito é pronunciado. Podemos explicar o fenômeno do apagamento do SD em presença de muito como um efeito de sua s-seleção, como decorrência da aversão de muito a graus máximos. Tanto achievements quanto accomplishments com transitivos exibirão grau máximo da progressão em direção à culminância com complemento SD. Porém, se o complemento for nu, não há leitura de episódio culminado. Não pronunciar o SD complemento é então um last resource para licenciar muito: assim se evita o clash com a exigência de muito de que não haja telicidade/culminância. Essa é a receita para intensificar o $\mathrm{SV}$, conservando a leitura de episódio único; quando não houver outras dimensões disponibilizadas pela natureza da eventualidade, a única leitura possível será a de iteratividade. As sentenças em (29) a (32) mostram que a pronúncia aberta do complemento não é permitida quando ele é um SD complemento de accomplishment ou achievement; nos demais casos, não há problema. A interferência do complemento quantificado na telicidade do SV depende da classe acional do verbo.

\footnotetext{
${ }^{11}$ Observe-se que a única leitura possível para (32e) é a de múltiplos episódios: ano após ano, um mesmo atleta sai vitorioso dessa competição anual; para (32a-b-c-d), também há a leitura de 'muitas vezes', mas há outras dimensões disponíveis: qualidade, volume etc.

${ }^{12}$ Em (32a) o complemento está no plural e no feminino, e em (32b/32e), no feminino, mas não há marcas de gênero ou número: não usamos muita nem muitas. A tradição gramatical (TG) distingue $\underline{\text { muito }}$ advérbio de muito pronome indefinido por critérios morfossintáticos: o advérbio é invariável, e o pronome apresenta marcas de número e gênero (quando ele "substitui" o SN complemento verbal).
} 


\subsection{O impacto da telicidade para verbos de movimento e eventualidades once-only}

Diversos verbos de movimento lexicalizam a maneira como o objeto se move (engatinhar etc.) e pertencem à classe acional "atividades"; outros lexicalizam o ponto de origem (sair etc.) ou o de chegada (vir etc.) e pertencem à classe acional dos "achievements". Já sabemos que, nesses, por serem télicos, a inserção de muito só vai gerar leitura iterativa $(33 \mathrm{a}, \mathrm{b})$. Se forçarmos uma leitura de episódio único, muito será agramatical (33c). Os verbos de movimento que são atividades são o novo interesse.

Sabe-se que, com a realização de um SD que denote o Path (o percurso), seja na forma de nomeação do destino (até a outra margem do rio, em (34b)), de nomeação do caminho, do ponto inicial ao final (a distância toda entre as duas margens, em (34c)), ou de nomeação do valor de medida da extensão percorrida $(\underline{\mathrm{km}}, \mathrm{em}(35 \mathrm{~d}))$, a sentença muda de atélica para télica, como mostrado em (34). Em (35b, c, d), vemos como essas sentenças recebem muito. Esperamos que ele possa entrar em (33a,b) e (35a), atélicas, mas não em (33c) nem em (35b, c, d), télicas. É o que ocorre:

(33) a. João vem muito aqui.

b. Maria sai muito à noite.

c. Maria saiu (*muito) de casa às $21 \mathrm{~h} 15 \mathrm{~min}$ de hoje.

(34) a. Eles nadaram por $20 \mathrm{~min} / *$ em $20 \mathrm{~min}$ esta manhã.

b. Eles nadaram até a outra margem do rio * por $20 \mathrm{~min} / \mathrm{em} 20 \mathrm{~min}$ esta manhã.

c. Eles nadaram a distância toda entre as duas margens * por $20 \mathrm{~min} / \mathrm{em} 20 \mathrm{~min}$ esta manhã.

d. Eles nadaram $3 \mathrm{~km}$ *por $20 \mathrm{~min} /$ em 20 min esta manhã.

(35) a. Eles nadaram muito esta manhã.

b. Eles nadaram (*muito) até a outra margem do rio esta manhã.

c. Eles nadaram (*muito) a distância toda entre as duas margens esta manhã.

d. Eles nadaram (*muito) $3 \mathrm{~km}$ esta manhã.

'Por $\underline{\boldsymbol{x}}$ tempo e em $\underline{\boldsymbol{x}}$ tempo (34) identificam SVs como como atélicos (34a) ou télicos (34b, c, d); 'esta manhã' garante a leitura de único episódio (34). Muito só é gramatical em atélicos (35a). Verbos de movimento famosos por dificilmente se tornarem télicos são empurrar/puxar (que expressam certa força aplicada a um objeto, para movê-lo); ao contrário, levar, pôr e trazer, que implicam a completude do trajeto, são inerentemente télicos. Vejamos como muito reage a isso:

(36) a. O pai levou os meninos à escola * por $20 \mathrm{~min} / \mathrm{em} 20 \mathrm{~min}$ hoje.

b. Pedro pôs o dicionário de volta na prateleira *por $20 \mathrm{~min} / *$ em $20 \mathrm{~min} /$ às $14 \mathrm{~h}$ de hoje. 
c. Eu empurrei o carrinho por $20 \mathrm{~min} / *$ em $20 \mathrm{~min}$ antes de sair do supermercado.

d. Eu puxei a corda por $20 \mathrm{~min} / *$ em $20 \mathrm{~min}$, mas depois não quis mais puxar.

(37) a. Foi o pai quem levou (*muito) os meninos à escola hoje.

b. *Pedro pôs muito o dicionário de volta na prateleira às $14 \mathrm{~h}$ de hoje.

c. Eu empurrei muito o carrinho antes de sair do supermercado.

d. Eu puxei muito a corda, mas depois não quis mais puxar.

Para as sentenças télicas com muito $(37 \mathrm{a}, \mathrm{b})$ só estará disponível a leitura de multiplicidade de eventos, com o adverbial hoje retirado; para as atélicas, é possível, na interpretação de que a sentença descreve um episódio singular, a leitura de intensidade: (37c) fala da força do empurrão, do tamanho do trajeto por que o carrinho foi empurrado etc.; e (37d) pode ser interpretada como aumentando o volume ou o comprimento da corda puxada, ou a duração do puxão, ou sua força...

Falaremos das leituras intensificacionais na próxima subseção. Por ora, vamos atentar ao fato de que sentenças télicas não as licenciam. Por exemplo, para (37a) não estão disponíveis leituras em que muito se aplica à velocidade do deslocamento, à distância percorrida etc. Caso (37a) seja lida como um episódio singular, inequivocamente será télica. Nesse contexto, muito não tem acesso a outras dimensões: a única forma de "desfazer" o grau máximo é criando iteratividade. Por isso, um episódio singular que não admita leitura iterativa será um ambiente hostil para muito. Sentenças once-only prototípicas, como as de invenção, criação, consumo ou destruição dos indivíduos denotados por seus complementos, não aceitam muito:

(38) a. Santos Dummont inventou (*muito) o avião.

b. Pixinguinha compôs (*muito) a famosa canção Carinhoso.

c. Foi naquelas águas frias que o Titanic naufragou (*muito).

d. Aqueles tripulantes morreram (*muito) de escorbuto.

e. Chapman assassinou (*muito) John Lennon.

f. Chomsky terminou (*muito) sua tese de doutorado em 1956.

As sentenças em (38) são télicas e denotam eventualidades singulares. Se o predicado verbal for quantizado (nos termos de Krifka) e se a soma de episódios tiver um supremo, um número máximo, seja singular ou plural, muito não poderá modificá-lo. Por não poder figurar em grau máximo, muito jamais figura em sentenças télicas. Um desdobramento disso é a não-ocorrência de muito com SDs que realizam o Path em verbos de movimento, transformando-os

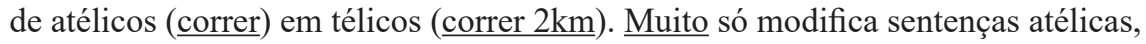
em que há ou um estado, ou um episódio em progresso ou uma soma indefinida (não-máxima) de episódios. 


\subsection{A incompatibilidade de muito com valores de medida expressos}

Examinando a modificação de SVs com verbos de medida (peso, custo etc.), vemos que muito não pode coocorrer com um SD que expressa um valor definido. ${ }^{13}$ Isso está de acordo com a análise proposta: se muito dá um grau alto, mas indefinido numa escala, espera-se que esse grau não possa ser identificado abertamente na mesma sentença, sob pena de haver um clash entre o requerimento de vagueza e o sintagma que expressa um valor exato. Essa predição se realiza:

(39) a. Ana está pesando $68 \mathrm{~kg}$.

b. Ana está pesando muito.

c. *Ana está pesando muito $68 \mathrm{~kg}$.

(40) a. Júlia media $53 \mathrm{~cm}$ ao nascer.

b. Para um bebê menina, até que Júlia media muito.

c. *Júlia media muito $53 \mathrm{~cm}$ ao nascer.

(41) a. Este anel de brilhante custa $\mathrm{R} \$ 15$ mil.

b. Este anel de brilhante custa muito; não vou comprar.

c. *Este anel de brilhante custa muito $\mathrm{R} \$ 15$ mil.

(42) a. A conferência demorou 2 horas.

b. A conferência demorou muito.

c. *A conferência demorou muito 2 horas.

O que os paradigmas de (39) a (42) mostram é que muito atua como valor da medida para esses verbos, uma medida vaga e indefinida em todas as sentenças (b) nessa sequência; sua função sintática e informacional é a mesma dos valores numéricos nas sentenças em (a). Sintaticamente, dois sintagmas não podem ter a mesma função; daí a duplicação do valor da medida, nas versões (c), ser agramatical. Além de não poder haver o duplo preenchimento da mesma função sintática, a realização do papel informacional não pode ser ao mesmo tempo definida e

${ }^{13}$ Há grande discussão na literatura sobre o estatuto estrutural desse SD. Por diferenças de comportamento em relação ao complemento de um verbo transitivo que forma um SV accomplishment, diversos autores defendem que não se trata propriamente de um complemento, nem de um argumento do verbo, mas sim de um adjunto, denominado "adjunto adverbial de medida"; alguns consideram verbos dessa natureza intransitivos. Não vamos entrar nesse debate sintático: queremos apenas chamar a atenção para o fato de que o SN que realiza o path em verbos de movimento, como em João correu $3 \mathrm{~km}$, pode não ser considerado um complemento, mas confere telicidade ao SV, transformando uma atividade num accomplishment; já o SD que segue um verbo de accomplishment como comer, por exemplo, em Pedro comeu uma pizza, é indiscutivelmente um complemento; isso mostra que a questão não pode ser reduzida à estrutura de complementação; é o grau máximo associado à telicidade que deve ser evitado. 
indefinida. ${ }^{14}$ Todas as sentenças gramaticais ((a) e (b)) dos paradigmas de (39) a (42) serviriam de resposta à uma única pergunta QU: 'quanto?'. Temos aí outra evidência de que muito expressa um grau, aqui numa escala de quantidade.

A incompatibilidade de muito com a realização do SD que expressa o valor da medida tem também como fonte a sua s-seleção. Defendemos que, assim como algum não pode figurar em uma sentença junto com a identidade do seu referente, como mostrado por Silva (2012) $)^{15}$, muito não pode figurar numa sentença junto com o nome/valor do grau de medida, por muito expressar um grau vago, inexato, indefinido e alto. Esses verbos tomam um argumento (ou adjunto? Não nos cabe decidir o estatuto estrutural do sintagma nominal pós-verbal) que informa uma medida.

A medida dada por muito em SVs de verbos que medem preço, altura, peso, idade, duração etc. é um valor quantificacional. A única leitura licenciada para muito em SVs achievements, a de iteratividade, é também uma leitura de quantidade: a soma de episódios produzida por muito é, como já observamos, vaga e indefinida. Escalas de quantidade desempenham um importante papel na telicidade de accomplishments, e de verbos de movimento, como já discutimos; verbos de medida tomam um "argumento" expressando o valor da medida sem efeito na sua telicidade. Mas muito não está limitado a denotar um grau (vago) numa escala de quantidade. Muito modificador de SV também é capaz de marcar um grau numa escala de qualidade, gerando leituras tradicionalmente designadas como "intensificacionais". É delas que vamos tratar na próxima seção.

\section{LEITURAS NÃO-QUANTIFICACIONAIS (DE INTENSIDADE)}

Nem todos os verbos admitem gradação, e um teste largamente difundido na literatura para identificá-los é exatamente verificar se aceitam ou não a inserção de muito no SV, gerando uma leitura de intensidade. Verbos graduais/escalares promovem leituras intensificadoras. Como identificar esses verbos? Um mesmo item lexical verbal pode permitir duas leituras. Por exemplo, o verbo trabalhar, em Pedro trabalhou muito, gera leituras quantificacionais (de iteratividade) e de intensidade (Pedro aplicou muito esforço, trabalhou por um tempo muito longo, deu uma contribuição de grande importância, teve grande participação no resultado obtido etc.). Já vimos que a classe acional (trabalhar é uma atividade) restringe

${ }^{14}$ A agramaticalidade da resposta (iii) à pergunta Quantos alunos vieram a essa aula? ilustra o duplo preenchimento sintático e o clash semântico de definitude com indefinitude:

(i)_Uns poucos.

(ii)_Apenas 2 .

(iii)_*Uns poucos apenas 2 .

${ }^{15} \mathrm{O}$ contraste entre (i), (ii) e (iii) mostra que algum exige ignorância do referente:

(i) Sei que um aluno esteve aqui, o Mário, porque vi quando ele entrou.

(ii) *Sei que algum aluno esteve aqui, o Mário, porque vi quando ele entrou.

(iii) Pelo estado da sala, infiro que algum aluno tenha estado aqui. Quem terá sido? 
as leituras quantificacionais com muito, mas ela não parece ter influência sobre as leituras intensificacionais disponíveis, que têm fontes lexicais ou pragmáticas. Nesta seção, vamos nos concentrar nas leituras não-quantificacionais, ${ }^{16}$ de intensidade, entendendo cada uma das sentenças em (43) como um episódio particular, de evento singular:

(43) a. A Terra está aquecendo muito.

b. Nevou muito este ano em Nova Iorque.

c. Picadas de abelha doem muito.

d. Meu irmão bebeu muito.

e. Essa minha amiga sabe muito.

f. Maria ama muito José.

g. Eu preciso muito de dinheiro.

i. Pedro amadureceu muito nos últimos meses.

j. Depois disso, aquela música caiu muito nas paradas de sucesso.

Muito eleva graus das mais diversas dimensões: de temperatura em (43a), de duração da emissão de neve ou da quantidade produzida em (43b); de dor em (43c), de quantidade de álcool ingerida ou do alcance de seus efeitos em (43d); da variedade de assuntos dominados ou da profundidade no domínio de determinado tópico em (43e); do grau de afeto em (43f); do grau de necessidade em (43g), da diferença entre o grau de maturidade de Pedro em dois momentos distintos em (43i); e da diminuição na preferência em (43j). Ficaria difícil dar conta dos dados de (43) sem analisar muito como um operador escalar. A diversidade de interpretações leva a concluir que a dimensão sobre a qual muito vai marcar um grau não-máximo elevado não é uma contribuição própria, mas do verbo que encabeça o SV. Muito opera sobre qualquer dimensão de grau que o SV lhe forneça, exigindo apenas que nessa dimensão graduável se possa indicar um grau mais alto, vago e não-máximo.

Embora não dê para esgotar as escalas verbais que geram leitura de intensidade, é certo que, por mais diversas que sejam, terão uma de duas fontes: ou a lexical ou a pragmática. Há verbos que descrevem seu argumento como apresentando um grau extremo (máximo) da propriedade. Nossa análise prevê que muito não combine com eles. A previsão procede:

(44) a. Maria ama muito José (=43f) (grau não-máximo)

b. Maria adora (*muito) José. (grau máximo)

c. Maria odeia (*muito) José. (grau máximo)

${ }^{16}$ Há leituras quantificacionais disponíveis para essas sentenças. Por ex., em (43b) muito pode aumentar o número de vezes em que nevou no período. Tais leituras iterativas, já comentadas, não vêm ao caso aqui. 
(45) a. Maria detesta (*muito) José. (grau máximo)
areciso muito de dinheiro (=43g) (grau não-máximo)

b. Eu quero muito ganhar dinheiro. (grau não-máximo)

c. Eu exijo (*muito) (ganhar) o dinheiro prometido. (grau máximo)

(46) a. A água do bule aqueceu muito. (grau não-máximo)

b. A água do bule esquentou muito. (grau não-máximo)

c. A água do bule ferveu (*muito). (grau máximo)

Vemos que, mesmo considerando escalas inerentes a verbos particulares, como (i) a de intensidade dos sentimentos de atração ou rejeição por outra pessoa (44); (ii) a da modalidade, que distingue a bulética da necessidade fraca e da forte (45): e (iii), a da temperatura que cresce (46), muito não pode figurar em SVs com verbos que denotam o atingimento do (ou o estado atual igual ao) grau máximo da escala.

Alguns verbos, quando modificados por muito, geram leitura intensificacional, e outros não. Por quê? Como saber se um verbo é escalar/gradual ou não, independentemente de aceitar modificação por muito? Fleischhauer (2010, 2016) distingue duas fontes de gradabilidade verbal: há propriedades graduais lexicalizadas pelo verbo, e há a gradação estendida, que é uma propriedade de eventualidade. Adotaremos a distinção semântica da autora, ${ }^{17}$ distinguindo entre as propriedades escalares de eventualidades e as provenientes ao significado idiossincrático de um verbo. O primeiro tipo agrega as leituras aspectuais de quantidade (medição da duração temporal, cardinalidade de eventos), e o segundo, as de intensidade.

Há eventos gradativos por sua natureza semântica, alguns por denotarem emissão de substância mensurável, produzindo luz, som, água etc. (vazar, chorar, iluminar etc.), outros por herança da escala adjetival (esquentar etc.), outros pela

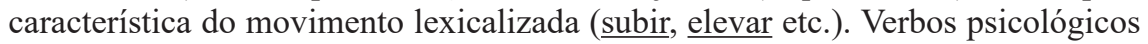

${ }^{17}$ A autora propõe lugares sintáticos distintos para os modificadores de um tipo de

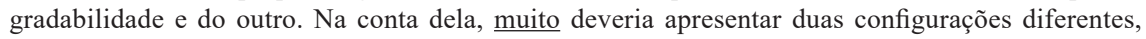
embora indiscerníveis por outros meios que não fossem a distinção entre leituras. Porém, para o $\mathrm{PB}$, não há testes capazes de verificar empiricamente em qual das duas posições sintáticas muito está, o que torna uma opção teórica adotar ou não a relação um-a-um entre posição estrutural e interpretação. Eu corri muito é uma sentença ambígua, e *Eu muito corri é agramatical. Há ainda outro obstáculo, empírico, à proposta de Fleischhauer. Na nota de rodapé (2) deste artigo, apresentamos alguns casos excepcionais em que muito precede o verbo, mas a especialização de sentidos não é verificada sequer aí. Quem muito quer nada tem pode ser interpretado tanto como um querer profundo (leitura intensificacional, de natureza lexical) quanto como um querer duradouro, prolongado (leitura aspectual). Não há associação óbvia entre a posição superficial de muito e certa leitura. Segundo Fleischhauer, o polonês e o alemão têm modificadores especializados para cada uma das duas formas de gradabilidade. Modificadores de escala estendida e modificadores de escala idiossincrática ocupam posições estruturais dedicadas. Ela não fala sobre o português, mas para o francês, o espanhol e o inglês, cujos modificadores não fazem distinção entre grau inerente e gradação estendida, assume que, mesmo a diferença não sendo visível, ainda assim há uma configuração sintática distinta para cada leitura do mesmo modificador. Porém, em PB, postular duas posições sintáticas dedicadas não é uma solução óbvia. 
como amar, gostar de, apreciar, divertir, temer, assustar vão fornecer escalas sobre a profundidade/intensidade do sentimento/sensação. Verbos incrementais, de

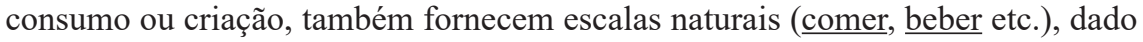
o fato de a relação parte-todo e as dimensões fixas da entidade referida por seu complemento fixarem uma progressão gradual para seu (des)aparecimento. Há ainda verbos que descrevem atividades escalares em quantidade ( $\underline{\text { cavar, empilhar, }}$ juntar etc.), pelo acúmulo crescente de (sub)produtos. Há eventualidades, ainda, que podem ganhar uma leitura de grau pelo nosso conhecimento enciclopédico ou de mundo sobre elas. Por exemplo, o nosso conhecimento sobre a quantidade adequada, o conteúdo apropriado etc. à contribuição na conversa nos permite dizer que alguém falou demais em dada ocasião, por informações que não deveriam ser divulgadas terem sido fornecidas então.

Mesmo reconhecendo esses diversos fatores como atuantes nas leituras intensificacionais (como é de esperar, visto que a inserção do item lexical na estrutura coloca muito em relações sintáticas e de escopo com outros itens e com projeções funcionais), ainda assumimos a definição de Fleischhauer (2014):

(47) Verbos de escalaridade lexical (ou intrinsecamente graduais) são aqueles que sempre expressam um grau em determinada dimensão, qualquer que seja seu contexto de uso.

Essa definição leva a prever que apertar muito terá pelo menos a leitura de um grau de arrocho; esticar muito terá pelo menos a leitura de um grau de estiramento etc. A definição em (47) prevê, corretamente, que verbos de posse e de troca de propriedade rejeitem sempre a modificação por muito, já que nem pertencimento nem transmissão de posse são graduáveis. A definição ainda determina que um verbo como comprar não seja considerado intrinsicamente gradual, pois não há nenhuma dimensão gradual que se mantenha disponível em qualquer contexto, mesmo que em determinadas construções exista a leitura iterativa, e, em outras, a de medição do volume da compra.

\section{1. 'Degree Achievements'}

Uma classe verbal relacionada a graus já bastante estudada é a dos Degree Achievements (DAs). ${ }^{18}$ Uma parte desses verbos é de base adjetival e "herda" o tipo de escala do adjetivo. Por exemplo, esquentar herda de quente a escala de temperatura e a direção da elevação. Sentenças com DAs que têm por base lexical adjetivos vagos, como quente, são ambíguas, em termos de telicidade:

(48) a. A sopa esquentou. (2 interpretações: grau máximo / não-máximo)

${ }^{18}$ Há duas posições concorrentes sobre esses verbos na literatura. Para alguns autores, eles tomam necessariamente um argumento de grau, determinado em sua entrada lexical (PIÑÓN, 2008; BALLWEG; FROSCH, 1979 etc.); para outros, eles se associam a graus, mas não entram com eles para a derivação (KENNEDY; LEVIN, 2008; KENNEDY, 2012; CAUDAL; NICOLAS, 2005; PIÑÓN, 2005; RETT, 2008). Não pretendemos decidir essa questão aqui. 
b. O dia esquentou. (somente grau não-máximo)

(49) a. A sopa esquentou muito. (somente grau não-máximo)

b. O dia esquentou muito. (somente grau não-máximo)

(50) a. A sopa esquentou (*muito) 15 graus.

b. O dia esquentou (*muito) 20 graus.

(51) a. A piscina encheu/ esvaziou.

b. A roupa que eu pus na corda secou.

(52) a. A piscina encheu muito.

b. A roupa que eu pus na corda secou muito.

Vemos que (48a) pode significar ou que a sopa atingiu a temperatura desejada, e o momento no qual o grau almejado é atingido marca a culminância do processo, gerando uma leitura télica; ou simplesmente pode comparar graus de temperatura em momentos distintos, constatando-se que o atual está acima do anterior - essa leitura é atélica. A diferença é contextual: num contexto há e, no outro não, o propósito de levar a sopa a atingir aquele estado em particular. Para (48b), a leitura télica não está disponível, pois nada podemos fazer para que o dia chegue à temperatura que considerarmos ideal. Há apenas a constatação de que, antes, a temperatura esteve menor que agora: leitura atélica. $\mathrm{O}$ fato de (48a) ter apenas uma interpretação, a atélica, após a inserção de muito (49a), assim como o próprio fato de essa inserção não poder ocorrer em (50), que traz um grau específico de temperatura, reforçam nossa análise. A leitura natural para (51) é a de que o grau máximo foi atingido, seja o limite máximo da piscina ( $100 \%$ no caso de encher, $0 \%$ no caso de esvaziar), seja o limite máximo de umidade na roupa lavada (ela está sem umidade, ou $100 \%$ seca). Num cenário com a piscina tendo água pela metade, mas acima do nível anterior, e com a roupa pingando água, embora menos do que estava há 30min, as sentenças de (51) não seriam verdadeiras. Elas são télicas. O contraste entre o par de sentenças (48) e o (51) reforça a influência da escala do adjetivo na telicidade do verbo. Vale observar, também, que, se as sentenças de (51) são exclusivamente télicas, a inserção de muito altera isso, produzindo um aspecto exclusivamente atélico (52). ${ }^{19}$ As sentenças (52) já não

\footnotetext{
${ }^{19}$ Kennedy e Levin (2008) propõem que a leitura télica e a atélica disponíveis para sentenças com DAs são geradas por medidas da progressão de um estado para outro (a measure of change). O movimento é sempre na direção de um grau maior, visto que escalas são unidirecionais; mas nem sempre há um grau máximo envolvido. A leitura télica ocorre quando um grau máximo foi alcançado. A leitura atélica é produzida quando há dois estados distintos do mesmo objeto comparado, cada um correspondendo a certo grau da propriedade, mas nenhum grau máximo é alcançado. Quando o adjetivo de base é absoluto, ou seja, marca um valor máximo, como em (51), os autores preveem que a leitura télica seja favorecida. Portanto, malgrado o nome, não há a telicidade típica de achievements, como classes acionais vendlerianas, nas sentenças com muito modificando SVs de verbos chamados na literatura de degree achievements. As leituras télicas são possíveis apenas na ausência de muito.
} 
são mais compatíveis com $100 \%$ de completude (da água na piscina) ou $0 \%$ de umidade (na roupa): elas só aceitam grau não-máximo. Embora adjetivos absolutos formem DAs télicos (51), e adjetivos relativos DAs ambíguos, ou vagos (48), com leitura télica e atélica, a modificação por muito produz apenas sentenças atélicas $(49,52) .{ }^{20} \mathrm{O}$ exame dos DAs confirma que muito produz exclusivamente escalas abertas, de grau não-máximo.

\subsection{Prevendo quando um SV fornecerá escalas abertas a muito}

As escalas aspectuais ou quantitativas são menos numerosas, e pudemos oferecer uma breve panorâmica delas em seções anteriores. Se, de um lado, o material (a dimensão gradual) sobre o qual muito vai atuar para criar a leitura intensificacional resiste a uma descrição completa, por outro lado o resultado da modificação por muito é totalmente previsível: o grau atribuído ao argumento relevante (esteja implícito ou abertamente realizado) aumenta consideravelmente, mas sem atingir um teto. Vamos exemplificar, com paráfrases, a comparação implícita contribuída por muito:

(53) a. O feijão está custando muito.

'O grau do preço atual do feijão supera largamente seu preço médio nos últimos tempos'

b. O sol brilha muito.

'O grau de brilho emitido pelo sol supera largamente o grau de brilho emitido por outros objetos brilhantes'

c. Pedro bebeu muito na festa.

'O grau de quantidade de bebida consumida por Pedro na festa em questão supera largamente o grau de quantidade de bebida consumida por Pedro em outras ocasiões'

Esse tipo de paráfrase será válido para qualquer sentença com muito modificando SV. Os requerimentos de que o grau exibido pelo argumento do predicado verbal modificado seja superior a um parâmetro, e, ainda, de que seja não-máximo, são parte das condições de verdade de uma sentença com muito em SV. Então, considerando que muito seleciona escalas onde possa marcar

${ }^{20}$ Com DAs cujo adjetivo de base é de grau máximo, muito é aceitável, mas modifica a leitura. Talvez o grau máximo no adjetivo ( $\underline{\text { cheio, }}$ vazio $)$ não se torne parte morfológica indelével da formação do DA relacionado (encher, esvaziar). De qualquer modo, ainda que assumamos o caráter especial, ambivalente, da aspectualidade (dos DAs) como proveniente de sua base adjetival, teremos que assumir algo a mais, pois, se podemos ver uma leitura télica em esquentei a sopa, é impossível dar uma leitura télica para o dia esquentou. É o mesmo verbo, com outro argumento. Não podemos então associar o grau exclusivamente à entrada lexical do verbo, mas temos de admitir que a conceptualização da eventualidade, ou nosso conhecimento de mundo sobre o evento descrito, interfira. Como isso se dá está além do escopo deste artigo. 
vagamente um grau não máximo, acima do parâmetro de comparação, o produto de sua modificação é previsível.

Uma corrente da literatura que discute sobre gradabilidade, baseada em Sapir (1944) e Bolinger (1972), defende que essa propriedade não é exclusiva de adjetivos, mas transcategorial. A gradabilidade no domínio verbal é mais complexa e intricada que no adjetival. Ela não é uniforme. É também indireta. Enquanto os adjetivos denotam propriedades, os verbos denotam indivíduos de certa natureza: eventualidades. Eventualidades são ancoradas no tempo-espaço, duram ou são instantâneas, culminam ou não, têm participantes etc. Verbos descrevem cenas, estados de coisas ou alterações de estados de coisas, e a composição do SV vai acrescentando novos detalhes a essa descrição, especificando mais a cena. São as propriedades da cena particular, descrita por aquele verbo, ou as das eventualidades em geral, que podem ou não ser escalares.

A natureza da escala intensificacional é idiossincrática, pois ela depende do significado lexical do verbo, que tem de se compor com a descrição da eventualidade. Isso pode parecer caótico, mas o conhecimento do significado individual dos verbos precisa ser armazenado pelo falante da língua, independentemente do uso de muito.

\section{FECHAMENTO: O ALCANCE DA PROPOSTA}

Mostramos que muito não modifica qualquer SV; e que nenhuma razão sintática permite prever sua distribuição. Mostramos que muito não distingue inacusativos de inergativos, nem seleciona certo número de argumentos. Tivemos mais sucesso com as classes acionais vendlerianas, pois muito de forma alguma entra em SVs que constituam achievements, e, se inserido em accomplishments, transforma-os em atividades. Isso porque a progressão em direção à culminância atinge o grau máximo em eventos télicos. Explicamos os casos de impossibilidade de muito modificar SV com complementos SDs: (i) em alguns casos, quando o complemento é o tema incremental, se realizado como um SD (quantizado), produz-se um accomplishment, e, assim, a leitura de episódio culminado, que é incompatível com muito (*Maria comeu muito a última maçã que tínhamos em casa); (ii) outro caso equivalente é o de verbos de movimento, em que a realização do Path na forma de um SD torna a eventualidade télica (*Pedro atravessou muito a avenida Brasil em 10 min ontem às 10h); (iii) outro tipo de conflito se dá com verbos de medida, já que, expressando um alto grau, vago e não-máximo, muito não pode coocorrer com um SD que nomeie um grau exato, definido, mapeado para o mesmo argumento, na mesma escala (*A mala pesa muito $32 \mathrm{~kg}$ ).

Dissemos que escalas em que o grau é expresso por um valor numérico, assim como escalas de medida da progressão da eventualidade em direção à culminância, em que o verbo tome como complemento um tema incremental quantizado, ou seja, um SD expressando uma soma máxima, são escalas quantitativas. Também é quantitativa a iteratividade, que multiplica episódios, denotando uma soma não-máxima, um número indefinido de repetições do mesmo tipo de eventualidade ao longo de um período indeterminado. A dimensão da iteratividade ou a leitura de múltiplos 
eventos ao longo de um período indefinido é disponibilizada por SVs que denotam eventualidades télicas (achievements e accomplishments). Os semifactivos, como bater à porta, são lexicalmente múltiplos, mas de subeventos, daí a leitura com muito ( $\mathrm{O}$ vizinho bateu muito à minha porta ontem às $14 \mathrm{~h}$ ), quando aplicada a um episódio singular, gerar uma interpretação de longa duração.

Todas essas interpretações de muito dependem da classe acional do SV. Sem dúvida, são propriedades de eventualidades, pois não são encontradas em outros tipos de indivíduos, como pessoas ou coisas (muita gente e muito caro não podem ser interpretados em termos de duração temporal ou de progressão para a culminância). A duração (a medida do período de tempo pelo qual a eventualidade se sustenta, continuadamente) também é uma dimensão dependente da classe acional, já que situar-se no tempo é uma propriedade de indivíduos que são eventualidades. Essas escalas quantitativas são (em maior ou menor medida) aspectuais. Mas há também leituras não-quantitativas de SVs modificados por muito, as chamadas interpretações intensificacionais. Elas levantam a questão da gradabilidade inerente a certos verbos.

Não é trivial prever que verbos, de uma mesma classe acional, proporcionarão ou não leituras intensificacionais, e os verbos que permitem leituras de intensidade podem pertencer a diversas classes acionais (com exceção dos achievements). Vimos que muito pode modificar alguns SVs de estado (Maria gosta muito de chocolate), mas não outros (*Maria está muito na Itália agora). Os verbos de estado modificados são inerentemente graduais. Também visitamos os Degree Achievements, considerados por alguns autores como herdeiros das escalas da base adjetival. Vimos que, não obstante ser fato que os adjetivos absolutos "geram" verbos télicos em PB, enquanto os adjetivos relativos "geram" verbos com leitura tanto télica quanto atélica, todo DA modificado por muito é atélico. O contraste entre isso e a incompatibilidade absoluta de muito com achievements pode se dever ao fato de a telicidade dos DAs de adjetivo absoluto ser indireta, composicional, e não inerente, ou pelo menos não apresentar o nível de inerência visto em accomplishments como chegar.

A leitura gradual disponibilizada por muito modificador de SV é composicional, mas depende da natureza da escala encontrada no seu domínio de modificação, e não é possível esgotar as escalas e dimensões graduais de verbos, assim como não seria possível listar todas as dimensões ligadas a adjetivos. Essa visão da escalaridade verbal implica que há no domínio verbal expressões intrinsicamente graduáveis (p.ex. crescer, esquentar) e outras não intrinsicamente graduáveis (p.ex. sentar, vender). Tal como no domínio dos adjetivos (alto é um adjetivo de grau, geográfico é um adjetivo sem grau). Claro, resguardadas as diferenças: adjetivos denotam (graus de) propriedades. Verbos denotam indivíduos de uma natureza especial, eventualidades, que estão associados a múltiplas propriedades e dimensões. A distribuição de muito modificador de SV é fruto de sua s-seleção.

Muito modificador de SV não é um caso isolado, uma excentricidade do PB. Tsujimura (2001) defendeu que totemo, do japonês, não se combina com escalas fechadas, mas somente com escalas abertas. Como já observado por Bolinger (1972), "verbos sem gradabilidade não aceitam intensificação". Analisamos muito como um reajustador de escalas (nos termos de Kennedy e McNally, 2005): esse operador precisa ser alimentado por uma escala, e vai transformar a estrutura dessa escala, produzindo com esse material uma escala aberta, em que o grau atribuído 
ao indivíduo será não-máximo, e, necessariamente, estará consideravelmente mais alto que o parâmetro de comparação.

\section{REFERÊNCIAS}

BACH, Emmon. The algebra of events. Linguistics and philosophy, v. 9, n. 1, pp. 5-16, 1986.

BALLWEG, Joachim; FROSCH, Helmut. Comparison and gradual change. In: Semantics from different points of view. Springer Berlin Heidelberg, 1979. pp. 75-89.

BOLINGER, Dwight. Degree words. Walter de Gruyter, 1972.

CAUDAL, Patrick; NICOLAS, David. Types of degrees and types of event structures. Event arguments: Foundations and applications, pp. 277-300, 2005.

CINQUE, Guglielmo. Adverbs and functional heads: A cross-linguistic perspective. Oxford: Oxford University Press, 1999.

DOETJES, J. Adjectives and degree modification. In: McNALLY, L.; KENNEDY, C. (Ed.). Adjectives and adverbs. Oxford: Oxford University Press, 2008. pp.123-165.

FLEISCHHAUER, Jens. Interaction of telicity and degree gradation of change of state verbs in German. Workshop on the Subatomic Semantics of Event Predicates. Barcelona, Spain. 2010.

FLEISCHHAUER, Jens. Degree gradation of verbs. Dissertations in Language and Cognition. Vol. 2. Düsseldorf University Press, 2016.

GOMES, Ana Quadros. Uma proposta de distinção semântica para os intensificadores muito e bem. Estudos Linguísticos, v. 40, n. 1, pp. 379-394, 2011.

HACKL, M. Comparative Quantifiers. Ph. D. thesis, MIT, 2000.

KENNEDY, Christopher ; LEVIN, Beth Measure of change: The adjectival core of degree achievements. In: McNALLY, Louise; KENNEDY, Christopher. (Ed.). Adjectives and Adverbs: Syntax, Semantics and Discourse. Oxford: Oxford University Press, 2008.

KENNEDY, Christopher; MCNALLY, Louise. Scale Structure and the Semantic Typology of Gradable Predicates. Language, v. 81, n. 2, pp. 345-381, 2005.

KENNEDY, C. (2012). The Composition of Incremental Change. In: Demonte, V. \& L. McNally (eds.): Telicity, Change, and State: A Cross-Categorial View of Event Structure. Oxford Studies in Theoretical Linguistics 39.

KRIFKA, Manfred. The origins of telicity. Events and grammar, v. 197235, 1998.

LAENZLINGER, C.; SOARE, G. On merging positions for arguments and adverbs in the Romance Mittelfeld. BRUGÈ, Laura et al. (Ed.). Contributions to the thirtieth 'Incontro di Grammatica Generativa'. Venezia: Libreria Editrice Cafoscarina, 2005. pp. 105-128. Disponível em: $<$ http://hdl.handle.net/10278/239>. Acesso em: 12/01/2017

LEMLE, Miriam. Guia teórico do alfabetizador. Editora Atica, 1994.

PIÑÓN, Christopher. Adverbs of completion in an event semantics. Perspectives on aspect, pp. 149-166, 2005. 
PIÑON, C. Aspectual composition with degrees. In: McNally, L. \& C. Kennedy (eds.). 183-219. 2008.

RETT, Jessica. Degree modification in natural language. Rutgers The State University of New JerseyNew Brunswick, 2008.

ROTHSTEIN, Susan. Structuring events: a study in the semantics of lexical aspect (Explorations in Semantics 2). Malden, MA \& Oxford: Blackwell, 2004.

SANCHEZ-MENDES, Luciana. A modificação de grau no domínio verbal em Karitiana: Evidência para Escalas indeterminadas. LIAMES: Linguas Indigenas Americanas, v. 15, n. 1, pp. 125-147, 2015.

SAPIR, Edward. Grading, a study in semantics. Philosophy of science, v. 11, n. 2, pp. 93-116, 1944. SOLT, Stephanie. A degree-based semantics for many and few. LSA Annual Meeting. 2007, Anaheim, CA(USA).

SILVA, Lidia Lima da. A manifestação das noções de ignorância e de conhecimento no português brasileiro: o caso de algum e (um) certo. 2012. Tese (Doutorado em Semiótica e Lingüística Geral) - Faculdade de Filosofia, Letras e Ciências Humanas, Universidade de São Paulo, São Paulo, 2012.

SMITH, Carlota. The parameter of Aspect, Studies in Linguistics and Philosophy. vol. 43. 1991.

TSUJIMURA, Natsuko. Degree words and scalar structure in Japanese. Lingua, v. 111, n. 1, pp. 29-52, 2001 .

VECCHIATO, Sara. On the Relative Position of beaucoup, guère, peu, rien, and trop in French. Working Papers in Linguistics, v.9, n.1-2, pp. 255-286, 1999.

VENDLER, Zeno. Linguistics in Philosophy. New York: Cornell University Press, 1967.

WACHOWICZ, Teresa Cristina; FOLTRAN, Maria José. Sobre a noção de aspecto. Cadernos de Estudos Linguísticos, v. 48, n. 2, 2011.

WACHOWICZ, Teresa Cristina. Marcas linguísticas de iteratividade em PB. Artigo publicado nos Anais do $6^{\circ}$ Encontro Celsul - Círculo de Estudos Linguísticos do Sul, de 2004. 2006.

WELLWOOD, Alexis. Measuring Predicates. Ph.D. dissertation, Maryland University, 2014. 